\title{
Prosthetic cost projections for servicemembers with major limb loss from Vietnam and OIF/OEF
}

\author{
David K. Blough, PhD; ${ }^{1 *}$ Sharon Hubbard, MS ${ }^{2}$ Lynne V. McFarland, PhD; ${ }^{3}$ Douglas G. Smith, MD ${ }^{4-5}$ \\ Jeffrey M. Gambel, MD, MPH, MSW; ${ }^{6}$ Gayle E. Reiber, PhD, MPH ${ }^{3,5}$ \\ ${ }^{1}$ Department of Pharmacy, University of Washington, Seattle, WA; ${ }^{2}$ Prosthetics Research Study, Seattle, WA; ${ }^{3}$ Health \\ Services Research and Development Service, Department of Veterans Affairs Puget Sound Health Care System, Seattle, \\ WA; ${ }^{4}$ Harborview Medical Center, Orthopedic Surgery and Rehabilitation Medicine, University of Washington, Seattle, \\ WA; ${ }^{5}$ University of Washington, Seattle, WA; ${ }^{6}$ Medical Corps, U.S. Army, Washington, DC; and Armed Forces Ampu- \\ tee Patient Care Program, Walter Reed Army Medical Center, Washington, DC
}

\begin{abstract}
This study projects prosthetic- and assistive-device costs for veterans with limb loss from Vietnam and injured servicemembers returning from Operation Iraqi Freedom (OIF) and Operation Enduring Freedom (OEF) to inform the Department of Veterans Affairs (VA) for these veterans' future care. The 2005 Medicare prosthetic device component prices were applied to current prosthetic and assistive-device use obtained from a national survey of 581 veterans and servicemembers with major traumatic amputations. Projections were made for 5-year, 10-year, 20-year, and lifetime costs based on eight Markov models. Average 5-year projected costs for prosthetic and assistivedevice replacement for the Vietnam group are lower than for the OIF/OEF cohort due in part to use of fewer and less technologically advanced prosthetic devices and higher frequency of prosthetic abandonment. By limb-loss level, for the Vietnam group and OIF/OEF cohort, 5-year projected unilateral upper limb average costs are $\$ 31,129$ and $\$ 117,440$, unilateral lower limb costs are $\$ 82,251$ and $\$ 228,665$, and multiple limb costs are $\$ 130,890$ and $\$ 453,696$, respectively. These figures provide the VA with a funding estimate for technologically advanced prosthetic and assistive devices within the framework of ongoing rehabilitation for veterans with traumatic limb loss from the Vietnam and OIF/OEF conflicts.
\end{abstract}

Key words: amputation, assistive device, cost projection, costs, limb loss, Markov model, OIF/OEF, prosthetics, rehabilitation, Vietnam.

\section{INTRODUCTION}

The Department of Defense (DOD) Rehabilitation Directive aims to return servicemembers with limb loss from Operation Iraqi Freedom (OIF) and Operation Enduring Freedom (OEF) to preinjury function and provide the option of returning servicemembers to Active Duty. As of June 2008, the DOD Amputee Patient Care Programs at Walter Reed Army Medical Center (Washington, DC), Brooke Army Medical Center (San Antonio, Texas), and Naval Medical Center (San Diego, California) have provided nearly 1,000 servicemembers with state-ofthe-art comprehensive rehabilitation care, including the provision of advanced technology, prosthetic and assistive

\footnotetext{
Abbreviations: ASR = age-sex-race-adjusted (death rates), DOD = Department of Defense, DSS = Decision Support System, MFCL = Medicare Functional Classification Level, OEF = Operation Enduring Freedom, OIF = Operation Iraqi Freedom, USD = United States dollar, VA $=$ Department of Veterans Affairs.

* Address all corr espondence to David K. Blough, PhD; Research Associate Pr ofessor, D epartment of Pharmacy, Box 357630, University of Washington, Seattle, WA 981957630; 206-685-9658; fax: 206-543-3835.

Email: dkblough@u.washington.edu

DOI:10.1682/JRRD.2009.04.0037
} 
devices, and training to restore function to the extent possible [1]. ${ }^{*}$ Servicemembers who benefit from these services continue to transition to the Department of Veterans Affairs (VA), where the prosthetic-device distribution practice allows all veterans with limb loss to receive prosthetic devices according to their functional level if deemed medically appropriate by their managing physician [2-3].

In 2008, the VA Prosthetic and Sensory Aids Service was the largest provider of durable medical equipment in the world, serving more than 1.9 million veterans with an annual budget of $\$ 1.4$ billion. $^{\dagger}$ In 2008, VA laboratories and contract prosthetic laboratories made or repaired prostheses for approximately 12,059 veterans at a cost of $\$ 74,656,247$, accounting for 5 percent of the Prosthetic and Sensory Aids Service budget. Veterans and servicemembers with major combat-associated limb loss are a part of the approximately 40,000 individuals with limb loss served by the VA Prosthetics and Sensory Aids Service. Veterans are not responsible for prosthetic device costs and are free to choose either a private contract prosthetist or a VA prosthetist. Sixty-one VA medical centers have nationally accredited prosthetics laboratories, and the VA has contracts with more than 600 small local businesses that meet the same accreditation standards [4-5]. An estimated 95 percent of all prostheses provided through the VA are fitted through this network of private contractors. $^{\dagger}$ The VA reimburses vendors based on negotiated contracts at approximately 5 to 10 percent less than Medicare rates. $^{\dagger}$

Previous literature evaluating costs in patients with limb loss focused on healthcare costs of different surgical procedures (such as immediate or delayed amputations [6], surgical reconstruction, and amputation [7-8]) or costs

\footnotetext{
* Scoville, Charles R. (Amputee Patient Care Service, Integrated Department of Orthopaedics and Rehabilitation, National Naval Medical Center, Walter Reed Army Medical Center, Washington, DC). Email to: Gayle E. Reiber (Program Analyst, Department of Prosthetic and Sensory Aids, VA Puget Sound Health Care System, Seattle, WA). Email on amputee monthly statistics for persons treated in all Army facilities. 2009 Jun 1.
}

${ }^{\dagger}$ Eckrich, Neal. (National Program Director, Prosthetic and Sensory Aids Service, VA Central Office, Washington, DC). Personal communication to: Gayle E. Reiber (Program Analyst, Department of Prosthetic and Sensory Aids, VA Puget Sound Health Care System, Seattle, WA). 2009 Mar 16. of different types of prosthetic devices [9-10]. No published research has projected lifetime costs incorporating the diverse combinations of prosthetic devices in current use today. This study on cost is part of a larger research project to provide VA clinicians and policy makers with information on recent changes in prosthetic- device utilization patterns, cost comparisons, and expert recommendations [2]. The purposes of this study are (1) to estimate costs of different types of prosthetic devices based on Medicare costs and (2) to then project future prostheticdevice costs based on reported prostheses use in two conflict-era cohorts (Vietnam and OIF/OEF).

\section{METHODS}

\section{National Survey}

Participants in the national Survey for Prosthetic Use (Appendix 1, available online only) are veterans from the Vietnam conflict (1961-1973) and servicemembers from the OIF/OEF conflicts (2000-2008) with at least one major traumatic amputation (excluding digit-only loss) occurring in the combat theater.

\section{Survey Participants}

All servicemembers with major limb loss (excluding digit-only) from OIF/OEF were invited to participate. We invited all Vietnam veterans with unilateral upper-limb loss, all with multiple limb loss, and a random sample of those with unilateral lower-limb loss to participate so we could obtain comparable numbers from both eras. Survey participants include 298 from the Vietnam conflict (65\% response rate) and 283 from the OIF/OEF conflicts (59\% response rate). Participants were surveyed using one of three methods (mail, telephone interview, or Web site) during 2007 and 2008.

\section{Expert Panel}

A panel of 25 experts in limb loss and prostheticdevice care, which consisted of researchers from VA, DOD, academia, and private-practice and veterans with limb loss from Vietnam and OIF/OEF conflicts (further described elsewhere [2]) advised the project team. The panel provided input on prosthetic and rehabilitation issues, model parameters, and data analysis and interpretation in multiple telephone conferences and a 3-day meeting. 


\section{Cost Estimation Overview}

Our approach to projecting prosthetic and assistive device costs was based on Medicare 2005 costs applied to prosthetic-device use patterns obtained from a national survey (Appendix 1, available online only). Figure 1 shows that the overall process of projecting costs began with collecting information from 298 veterans from the Vietnam conflict and 283 servicemembers from the OIF/ OEF conflict with major limb loss (Step 1). In Step 2, we developed a cost matrix to determine the average cost of the prosthetic-device system. The costs vary by type of prosthetic device, level of limb loss, and functional capability. In Step 3, by applying costs estimated by the cost matrix, we created a cost file to estimate the total cost for each survey participant based on current prosthetic- and assistive-device use reported in the survey. In Step 4, we developed eight Markov models specifying four types of limb loss (unilateral lower, unilateral upper, bilateral upper, and other multiple limb loss) for the two conflicts (Vietnam and OIF/OEF) to model the data. In Step 5, the results for 5-year, 10-year, 20-year, and lifetime projected prosthetic- and assistive-device costs were calculated. Detailed explanations of each step of the model follow.

\section{Step 1: National Survey Inputs}

Veterans and servicemembers participating in the national survey (Appendix 1, available online only) provided information on their age, military conflict, and the level of limb loss for each injured limb.

\section{Prosthetic Device Types}

The survey provided pictures and brief descriptions of groups of prosthetic device systems and queried servicemembers on the types and quantities of prosthetic devices ever received. Currently used prosthetic device data included type, number, and frequency of use. Survey participants also indicated the frequency of use for each prosthetic device type: daily, weekly, monthly, or one to two times per year. Replacement frequencies were collected for each type of prosthetic device.

Current use of assistive devices was also reported. Assistive devices included manual and electronic wheelchairs; walking aids (canes, crutches, walkers); and for

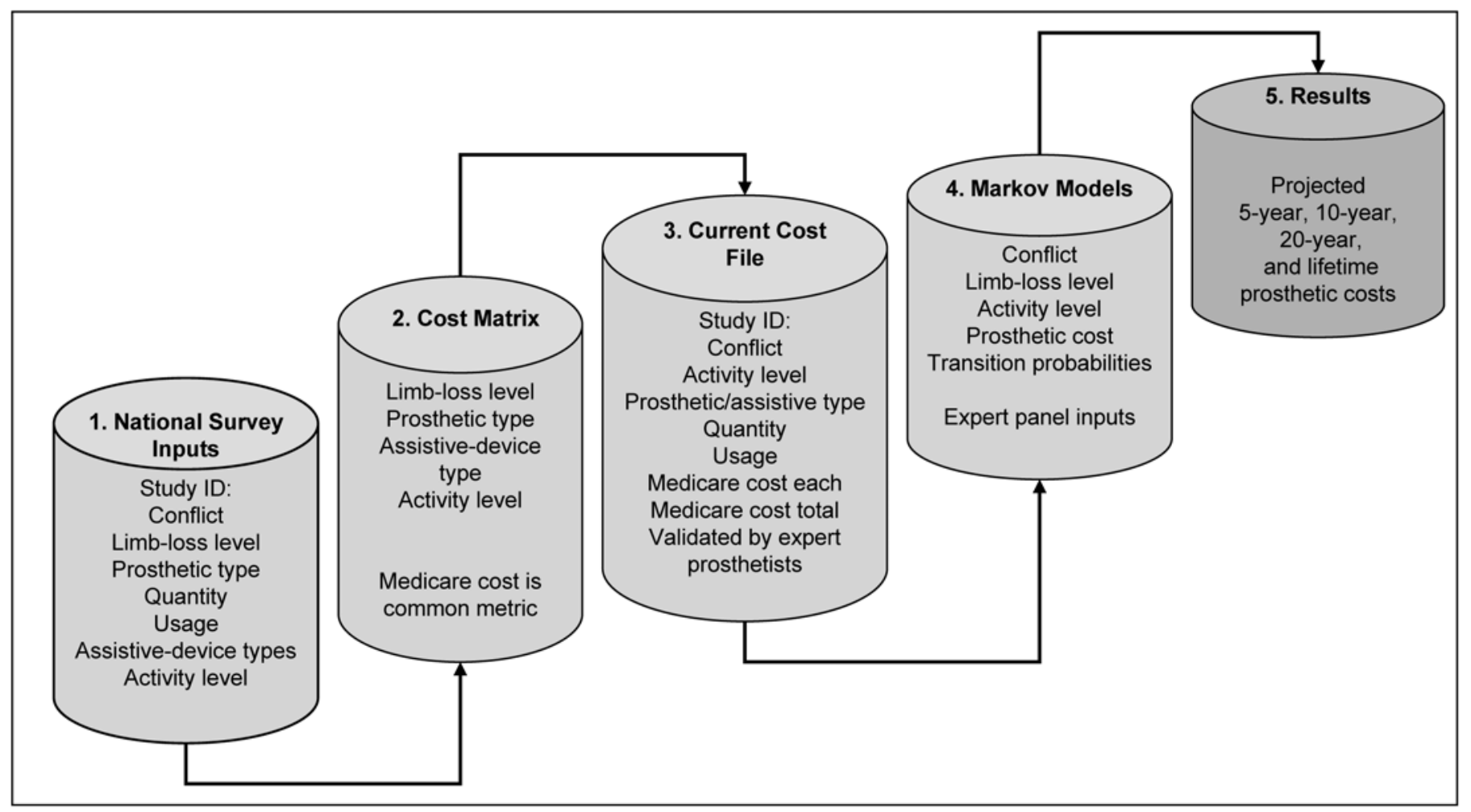

Figure 1.

Steps involved in cost projections for Vietnam and Operation Iraqi Freedom/Operation Enduring Freedom groups with major traumatic limb loss. 
those with upper-limb loss, upper-limb attachments to facilitate activities of daily living (including car modifications).

\section{Level of Limb Loss}

Each individual's most proximal limb-loss level was used as his or her level of limb loss for the Markov models. Limb loss was grouped as unilateral lower, unilateral upper, bilateral upper, and multiple limb loss. The levels of lower-limb loss were categorized as partial foot, ankle disarticulation, transtibial, knee disarticulation, transfemoral, hip disarticulation, and transpelvic (none reported in survey). Upper-limb loss was grouped into seven levels: partial hand, wrist disarticulation, transradial, elbow disarticulation, transhumeral, shoulder disarticulation, and forequarter (none reported in survey). Detailed descriptions of survey participants with unilateral lower-limb loss [11], unilateral upper-limb loss [12], and multiple limb loss [13] and survey participants not using prosthetic and assistive devices [14] are described in other articles in this issue.

\section{Functional Level}

Currently, the most widely recognized system for assessing functional capability for those with lower-limb loss is the Medicare Functional Classification Level (MFCL) [15-16]. MFCLs are typically assigned by the physician and rehabilitation team and are descriptors of a patient's potential functional capability. Most patients, including many veterans and servicemembers, are not aware of the MFCL numeric value assigned by their current prosthetics provider. To facilitate the survey participants' self-assessment of their current lower-limb functional capability level, project experts modified the MFCL tool and developed a hierarchy of increasing function in daily tasks and activities from Level 1 to Level 7, as shown in Table 1.

\section{Step 2: Cost Matrix}

The objective of the cost matrix was to estimate the cost of typical prosthetic device systems used by survey participants. We found that this cost depends on three characteristics: the type of prosthetic device (by varying degrees of technology), the level of limb loss, and the functional capability. For lower-limb loss, more than 400 unique prosthetic-device-type cost scenarios exist, predicated on six major prosthetic device types, seven limb-loss levels, and seven functional capability levels.
Table 1.

Functional capability levels of those with lower-limb loss in Survey of Prosthetic Use (Appendix 1, available online only).

\begin{tabular}{|c|c|}
\hline $\begin{array}{l}\text { Functional } \\
\text { Level }\end{array}$ & Prosthetic Use Description \\
\hline 7 & $\begin{array}{l}\text { High-impact activities: Usually jog or run } \\
\text { and do high-impact sports (e.g., skiing, } \\
\text { mountain climbing). }\end{array}$ \\
\hline 6 & $\begin{array}{l}\text { Low-impact activities: Can run but usually do } \\
\text { low-impact activities (e.g., swimming, golf- } \\
\text { ing, hiking). }\end{array}$ \\
\hline 5 & $\begin{array}{l}\text { Can walk with varying speeds (slow to } \\
\text { fast) over uneven surfaces and barriers. }\end{array}$ \\
\hline 4 & $\begin{array}{l}\text { Community walker (walk around community } \\
\text { over short barriers; can walk on uneven } \\
\text { surfaces). }\end{array}$ \\
\hline 3 & $\begin{array}{l}\text { Household walker (walk around the house } \\
\text { on even surfaces only). }\end{array}$ \\
\hline 2 & $\begin{array}{l}\text { Do not need help to transfer but cannot } \\
\text { walk. }\end{array}$ \\
\hline 1 & Need help to transfer; cannot walk. \\
\hline
\end{tabular}

The first important characteristic influencing cost is the type of prosthetic device system. Therefore, the first step was to categorize prosthetic devices within a group sharing a similar level of technology. Given the wide range of prosthetic devices and suppliers, it was impractical to attempt specific identification of each component or supplier for a prosthetic device for each survey participant. In lieu of specific device identification and costing, the survey grouped prosthetic devices into categories appropriate to prosthetic component technology. These six "prosthetic device types" for lower-limb loss devices included microprocessor, hybrid, mechanical, sports/specialty, waterproof, and cosmetic.

The second important cost characteristic is the level of limb loss. In our survey, 87 percent of participants with unilateral lower-limb loss were at the transtibial or transfemoral level. Therefore, for lower-limb loss, we focused our estimates on these two limb-loss levels. Costs of lower limb prosthetic device systems were estimated for each level of limb loss within functional levels and confirmed by the expert panel. For example, for functional levels 4 to 7 , microprocessor prosthetic device systems had compiled costs for the following levels of lower-limb loss: partial foot $(\$ 14,187)$, ankle disarticulation $(\$ 16,356)$, transtibial $(\$ 16,690)$, knee $(\$ 45,563)$, transfemoral $(\$ 45,563)$, hip $(\$ 45,633)$, and transpelvic disarticulation $(\$ 49,208)$. 
The third cost characteristic is the functional capability of the person with limb loss and the types of activities done in daily life. Functional capability plays a significant role in the cost of the components used to create a prosthetic device system. In addition, for those whose daily living activities include high-impact occupational or recreational activities, we found that not only were more devices used but also a wider diversity of prosthetic devices was in use.

The last step in developing the cost matrix was to estimate total costs based on the three cost characteristics. The costs for transtibial and transfemoral levels were determined by assigning Medicare L-codes appropriate for prosthetic device type, limb-loss level, and functional level. The cost for each L-code was assigned using the median Medicare cost for the 50 states and the District of Columbia. Our cost reference was the "Fee Schedule
Update for 2005 for Durable Medical Equipment, Prosthetics, Orthotics, and Supplies (DMEPOS)" for noninstitutional providers [17].

Table 2 provides the specific L-codes, descriptions, and 2005 Medicare costs for typical components of a microprocessor knee at the transfemoral level to illustrate the process. The total cost of a prosthetic device system is $\$ 45,563.17$. The cost matrix for transfemoral-level limb loss is shown in Table 3: the compiled cost is at the junction of the participant's functional capability (rows) and the type of prosthetic device (columns). We developed a cost matrix for each level of limb loss (data not shown). The cost for the prosthetic device described in Table 2 is found in the microprocessor column in Table 3 for functional levels 4 to 7 . No costs are assigned for

Table 2.

L-codes and Medicare 2005 costs for transfemoral microprocessor knee.

\begin{tabular}{|c|c|c|c|c|}
\hline \multirow{2}{*}{ L-Code } & \multirow{2}{*}{ Healthcare Common Procedure Coding System* } & \multirow{2}{*}{ Quantity } & \multicolumn{2}{|c|}{2005 Median (\$) } \\
\hline & & & Each & Total \\
\hline L5321 & Def mold socket SACH ft endo & 1 & $2,881.74$ & $2,881.74$ \\
\hline L5981 & Flex-walk sys low ext prosth & 1 & $2,590.78$ & $2,590.78$ \\
\hline L5930 & Hi activity frame & 1 & $2,729.48$ & $2,729.48$ \\
\hline L5828 & SNS & 1 & $2,376.90$ & $2,376.90$ \\
\hline L5856 & MPC swing \& stance & 1 & $19,264.21$ & $19,264.21$ \\
\hline L5848 & Stance extension control & 1 & 863.12 & 863.12 \\
\hline L7368 & Battery charger & 1 & 405.09 & 405.09 \\
\hline L5845 & Stance flexion & 1 & $1,438.67$ & $1,438.67$ \\
\hline L5984 & Endoskeletal axial rotation & 1 & 518.65 & 518.65 \\
\hline L5637 & Total contact & 1 & 266.74 & 266.74 \\
\hline L5631 & Acrylic socket & 1 & 352.37 & 352.37 \\
\hline L5649 & Ischial containment & 1 & $1,663.03$ & $1,663.03$ \\
\hline L5651 & Flex inner socket ext fra & 1 & 963.10 & 963.10 \\
\hline L5679 & Socket insert w/o lock mech & 2 & 500.61 & $1,001.22$ \\
\hline L5698 & Silesian belt & 1 & 96.24 & 96.24 \\
\hline L5781 & Lower limb pros vacuum pump & 1 & $3,211.60$ & $3,211.60$ \\
\hline L5705 & Custom shape cover & 1 & 818.55 & 818.55 \\
\hline L5964 & Flex cover system & 1 & 848.66 & 848.66 \\
\hline L8430 & Prosthetic sock multi ply & 12 & 19.51 & 234.12 \\
\hline
\end{tabular}


microprocessor devices at the transfemoral level at lower functional levels, because these devices are not used for nonambulatory or household walkers (according to the opinions of the expert panel).

Costs of upper-limb prosthetics were estimated by grouping upper-limb prosthetic devices by device types and level of limb loss. Unlike the lower-limb prosthetic cost matrix, functional capability was not considered for upper-limb prosthetic devices because no equivalent system, such as the MFCL used for lower limbs, is in current use for upper-limb loss. Survey participants with upperlimb loss also had fewer prosthetic device options than those with lower limb loss. Twenty-eight potential cost scenarios were evaluated for upper-limb use based on four major prosthetic device types (myoelectric, hybrid, mechanical, and cosmetic) and the seven limb-loss levels. Final survey data indicated that 71 percent of survey participants with upper-limb loss were either at the transradial or transhumeral level; thus, prosthetic device cost development focused primarily on these two limb-loss levels. The prosthetic device costs for the remaining five levels of limb loss were derived by decreasing or increasing the transradial or transhumeral values as deemed appropriate by the expert panel. For example, myoelectric prosthetic devices had compiled costs for the following levels of upper limb loss: partial hand $(\$ 18,703)$, wrist $(\$ 19,922)$, transradial $(\$ 20,329)$, elbow (not appli- cable), transhumeral $(\$ 59,664)$, shoulder $(\$ 61,655)$, and forequarter disarticulation $(\$ 62,271)$.

\section{Step 3: Current Cost File}

For each survey participant, we accumulated the estimated costs over time for all devices used. This total cost is based on the number of past and current prosthetic devices reported in the survey and on the application of costs from the cost matrix (based on prosthetic device type, level of limb loss, and functional capability). For modeling purposes, total costs were stratified by combat cohorts (Vietnam and OIF/OEF) and the following limbloss groups: unilateral lower, unilateral upper, bilateral upper, and multiple limb loss.

\section{Step 4: Markov Models for Cost Analysis}

Markov models, commonly used in chronic disease research, were used to make cost projections over four different time horizons associated with limb loss: 5 years, 10 years, 20 years, and lifetime (up to 100 years) [18$22]$. Our cost analysis included only the projected costs of prosthetic devices and assistive devices. The model estimates did not include costs for repair and increases in costs due to future technologies. Therefore, these cost estimates are conservative.

In defining our model, we used the set of principles for cost-effectiveness analysis developed by Weinstein et al.

Table 3.

Cost matrix for costs of prosthetic device types by functional level for transfemoral limb loss based on Medicare 2005 costs in 2005 dollars.

\begin{tabular}{|c|c|c|c|c|c|c|c|}
\hline Functional Level & $\begin{array}{l}\text { No Prosthesis } \\
\text { Use }\end{array}$ & $\begin{array}{c}\text { Micro- } \\
\text { Processor }\end{array}$ & $\begin{array}{l}\text { Hybrid- } \\
\text { Mechanical/ } \\
\text { Electronic }\end{array}$ & $\begin{array}{l}\text { Traditional/ } \\
\text { Mechanical }\end{array}$ & $\begin{array}{l}\text { Specialty/ } \\
\text { Running }\end{array}$ & $\begin{array}{l}\text { Water- } \\
\text { proof }\end{array}$ & $\begin{array}{l}\text { Passive/ } \\
\text { Cosmetic }\end{array}$ \\
\hline 1: Need help to transfer; cannot walk. & $\mathrm{N} / \mathrm{A}$ & $\mathrm{N} / \mathrm{A}$ & N/A & N/A & $\mathrm{N} / \mathrm{A}$ & $\mathrm{N} / \mathrm{A}$ & $\mathrm{N} / \mathrm{A}$ \\
\hline $\begin{array}{l}\text { 3: Household walker (walk around } \\
\text { house on even surfaces only). }\end{array}$ & N/A & N/A & N/A & 9,360 & 22,906 & 19,649 & 10,967 \\
\hline $\begin{array}{l}\text { 5: Can walk with varying speeds (slow to } \\
\text { fast) over uneven surfaces and barriers. }\end{array}$ & N/A & 45,563 & 35,196 & 18,713 & 22,906 & 19,649 & 10,967 \\
\hline $\begin{array}{l}\text { 6: Low-impact activities: Can run but usu- } \\
\text { ally do low-impact activities (e.g., } \\
\text { swimming, golfing, hiking). }\end{array}$ & N/A & 45,563 & 35,196 & 21,815 & 22,906 & 19,649 & 10,967 \\
\hline
\end{tabular}


[23]. Our Markov models consist of four basic components: (1) a basic model structure known as the cycle tree; (2) functional states (the functional levels) with corresponding prosthetic cost distributions; (3) transition probabilities, modeling the likelihood of a survey participant moving from one functional state to another over time; and (4) prosthetic and assistive device assumptions. Methodological details of each component of the models follow.

\section{Basic Model Structure}

Data on current prosthetic device use were available from survey participants. The expert panel then recommended the basic structure and transition probabilities for our models given the absence of prior published research in this area. We began with a 1-year cycle length to allow for rapid changes in prosthetic device use during the 5 years following the first postamputation year. After the fifth year, the probabilities of transitioning to other functional levels were decreased to reflect the relative stability in prosthetic device use during later years.

\section{Functional States}

The functional states from Table 1 are seven levels of increasing functional ability for daily physical tasks and activities. The expert panel agreed that each year subjects would likely remain in the same functional state, or if they moved, it would be either up or down one functional level, not two or more levels. In Figures $\mathbf{2}$ and $\mathbf{3}$, death is included as a component of the Markov models, since these models simulate the life experience of veterans and servicemembers with limb loss.

\section{Transition Probabilities}

The expert panel advised on transition probabilities (the probability of moving from one functional level to another) for the Markov model. In general, the consensus from the expert panel defined general trends of changing from one functional level to another over 1 year but was unable to define transitions for every year in the model. Because of a lack of evidence regarding transition probabilities for those with limb loss, we accounted for this uncertainty in the models. Specifically, we treated transition probabilities, not as fixed, known quantities, but as values that change over the simulated time in the model through the use of probability distributions. The model output reflects this variability because each year in the simulation, a transition probability is drawn at random from the specified distribution. The year-to-year variability captures the

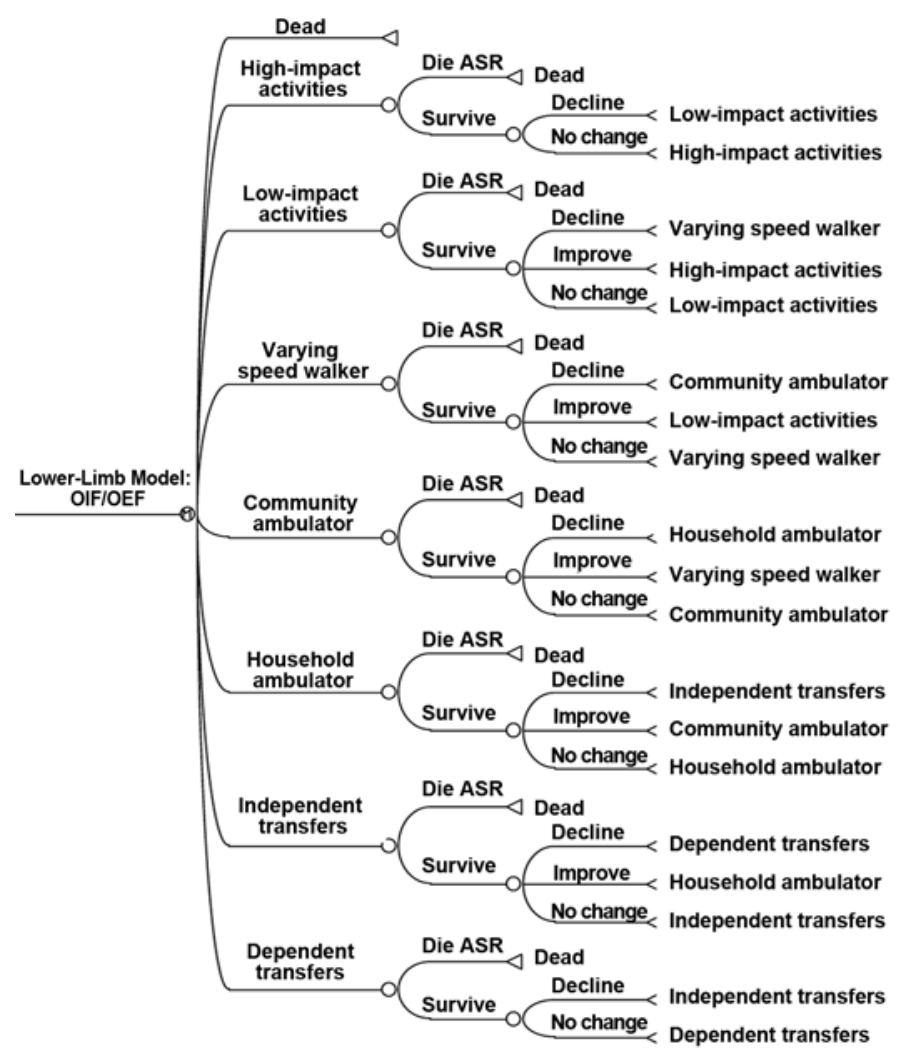

Figure 2.

Markov model for unilateral lower limb and multiple limbs for Operation Iraqi Freedom/Operation Enduring Freedom (OIF/OEF) group. ASR = age-sex-race-adjusted death rates.



Figure 3.

Markov model for unilateral upper limb and bilateral upper limbs for Operation Iraqi Freedom/Operation Enduring Freedom (OIF/OEF) group. ASR = age-sex-race-adjusted death rates.

range of prosthetic device use and function in our population reported in the national survey.

We used the Dirichlet distribution [24] to model the transition from a given functional level to one level 
higher, one level lower, or remaining at the same level. Based on expert panel discussions, a baseline Dirichlet distribution was used for the first 5 years of transitions starting 1 year postamputation and a second Dirichlet distribution was used for transitions after 5 years. This general rule was applied to all individuals, regardless of individual activity level. The baseline distribution, based on expert panel consensus, has probabilities of transition at $0.1,0.1$, and 0.8 . These indicate that, in any given year, the probability of moving to a functional state one level higher is 0.1 , the probability of moving one level lower than the current level is 0.1 , and the probability of remaining in the current functional state is 0.8. Similarly, for transitions after 5 years, the expected transition probabilities change to $0.05,0.05$, and 0.9 , for moving to a higher level, moving to a lower level, or staying the same, respectively. Based on their experience, the expert panel indicated that fewer transitions occur after 5 years, and those that do are primarily related to weight gain or weight loss; therefore, the transition probabilities used in the 5-year period were also used for the estimates for the 10-year, 20-year, and lifetime periods. The mean values for these transitional probabilities provided by the expert panel were used as the mean value for new distributions as the model was cycled.

When a simulated person in the model dies, he or she transitions to the death state. We obtained transition probabilities to the death state as age-sex-race-adjusted (ASR) death rates from published vital statistics. Separate death rates were used for the OIF/OEF group [25] and the Vietnam group [26] because of the groups' different age-dependent mortality probability. These probabilities are given in 1-year increments for the OIF/OEF group and in 5-year increments for the Vietnam group. Linear interpolation was used to determine intermediate yearly death rates for the Vietnam group. Both mortality tables showed yearly survival rates after the age of 100 to be zero; therefore, lifetime costs were modeled on a time horizon of 100 years.

The cycle tree for OIF/OEF unilateral lower- and multiple-limb groups is shown in Figure 2. Similarly, Figure 3 shows the cycle tree for OIF/OEF unilateral and bilateral upper-limb groups. In each figure, the first node on the left represents a summary of the initial conditions of the model at 1 year postamputation. The second column displays the functional levels from Table 1. At each functional state, the model assigned costs for each simulated year and the transition probability specifications associated with each option. Each branch from the func- tional state circle shows the transition to either death using mean ASR death rate or survival at a higher, lower, or the same level of function for another year. Each simulated year is represented by one cycle of the model, traversing the figure from left to right once. For example, to project 20-year cumulative average costs, the model simulates a large cohort of survey participants moving (cycling) through the tree 20 times. In the Markov model, functional-level costs were randomly sampled from the resulting distribution of costs. All costs within an activity level were equally likely to be drawn on each iteration of the cost simulation, accounting for the variability in costs.

To assess the robustness of our transition probabilities, we performed a formal sensitivity analysis [23]. Since no empirical studies are available to inform selection of these transition probabilities, we simulated costs using a "worst case" Dirichlet distribution; that is, one in which all probabilities between 0 and 1 are equally likely. This simulation is achieved by specifying a distribution with all probabilities set to 0.33 . Thus, the transition probabilities for each of the three outcomes are equally likely. Given the lack of data, we considered this approach analogous to that suggested by Briggs et al. [24].

\section{Model Assumptions and Considerations}

First, a key Markov model assumption is that the functional level to which a subject moves in a given year depends only on his or her functional level the previous year, not on prior years. By defining a cycle length of 1 year for our model, this assumption was warranted [19]. Second, the value of a dollar today is not the same as its future value. Discounting future cost projections to a baseline time is important to assess the present value of all projected costs. Health economists agree that discounting is necessary, and the 3 percent discount rate, supported in the literature [23], was used to compute the present value of all cost projections relative to the year 2005. Third, we account for important aspects of prosthetic device use in this simulation by including the number of devices used and types of prosthetic devices from the reported data in the national survey. Fourth, cost variability was accounted for by sampling within the range of observed costs of our study participants. Fifth, the costs of repairs, service, and new prosthetic device technology are not included in the models. Sixth, the expert panel contributed to the model structure shown in Figures $\mathbf{2}$ and $\mathbf{3}$ by setting baseline transitional probabilities for the first year and for later years. Weinstein et al. indicate expert opinion is a legitimate method for assessing parameters, provided either 
that these parameters are shown not to affect the results importantly or that a sensitivity analysis is reported on these parameters with a clear statement that results are conditional upon the subjective estimate(s) [23].

After specifying the structure of the model, the functional states and costs, and the probabilities of moving between functional states, we used the model to simulate cost accrual over the various time horizons by simulating a group of survey participants moving through the model 1,000 times (at which time all participants reached the endpoint of death). In each cycle, a simulation of 1-year, functional-level cost distributions and transition probabilities was sampled from their corresponding databases. Each simulated participant then traversed the cycle tree with the given probabilities and costs to obtain costs for that simulated year. This was repeated for the number of years for the given time horizon $(5,10,20$, or lifetime). Lifetime costs were obtained by repeatedly cycling through the tree until all participants of the simulation group died. This resulted in 1,000 projected average costs, all different, because of the sampling of costs and the sampling of transition probabilities.

For the simulations, the proportion of the group initially in each functional level was estimated by the corresponding proportion reported in our survey data. Since these proportions were obtained from a sample of servicemembers, they vary from the true population proportions. The Dirichlet distribution was used to allow for the sampling uncertainty in these functional-level frequencies, with marginal means corresponding to the frequencies observed from the questionnaire.

\section{Statistical Methods}

Summary statistics, including mean, standard deviation, and quantiles were computed for the following categories: unilateral upper-limb loss, unilateral lower-limb loss, bilateral upper-limb loss, and multiple limb loss in the Markov models. Markov models and simulations were conducted using TreeAge Pro 2008 software (TreeAge Pro; Williamstown, Massachusetts). Details on Markov models are provided in other articles on modeling costs [27], practical aspects of modeling [28], and recent developments with technical and mathematical details [29-30].

We used Stata 9.2 (StataCorp; College Station, Texas) for comparisons of prosthetic use. Statistical significance was based on chi-square (categorical data) or Student $t$-test (continuous data). The level of significance was for a two-sided $p<0.05$.

\section{RESULTS}

The projected costs are based on four limb-loss groups within each of the two conflict groups (298 Vietnam and 283 OIF/OEF participants): unilateral lower-limb loss with 47 and 50 participants, respectively; unilateral lowerlimb loss, 178 and 172, respectively; bilateral upper-limb loss, 6 and 7, respectively; and other types of multiple limb loss, 67 and 54, respectively. The average number of prosthetic devices in current use differs between conflict groups. There were significant differences in prosthetic device use in the two conflict groups. Reiber et al. reported 78 percent of the Vietnam cohort currently use prosthetic devices, while 90 percent of the OIF/OEF cohort are current users of prosthetic devices [2]. Table 4 shows that current prosthetic use by limb-loss level was up to threefold higher in the OIF/OEF group than the Vietnam group, no matter which level of limb loss.

The Markov models' cost projections across all time horizons for unilateral upper-limb groups are presented in Table 5. The average 5-year projected cost is $\$ 31,129$ for the Vietnam veteran group, in which only 70 percent currently use prostheses, and of these, 78 percent are traditional mechanical devices. The OIF/OEF group with unilateral upper-limb loss use nearly twice as many prostheses as the Vietnam group. A higher proportion, 76 percent, use prostheses (46\% myoelectric and 38\% mechanical); thus, their average 5-year cost projection $(\$ 117,440)$ is higher than that of the Vietnam group. Note that the maximum simulated 20-year costs for the Vietnam cohort exceed the maximum lifetime costs. This may occur when simulated data are based on sampling from a range of probabilities, and the lower costs in the lifetime follow-up populations are due to lower survival frequencies and therefore fewer prosthetic devices are used.

Table 6 shows cost projections in those with unilateral lower-limb loss. Prostheses were used by 84 percent

\section{Table 4.}

Average number of reported currently used prosthetic devices by type of limb loss (mean \pm standard deviation) for Vietnam and OIF/OEF survey participant groups.

\begin{tabular}{lll}
\hline \multicolumn{1}{c}{ Limb Loss } & Vietnam & OIF/OEF \\
\hline Unilateral Upper Limb & $1.0 \pm 0.8$ & $1.8 \pm 1.7^{*}$ \\
Unilateral Lower Limb & $1.2 \pm 0.9$ & $3.1 \pm 2.5^{*}$ \\
Bilateral Upper Limb & $2.2 \pm 3.0$ & $4.7 \pm 3.7$ \\
Other Multiple Limbs & $1.8 \pm 1.5$ & $5.7 \pm 4.9^{*}$ \\
*p<0.05 compared with Vietnam group. \\
OIF/OEF = Operation Iraqi Freedom/Operation Enduring Freedom. \\
\hline \hline
\end{tabular}


JRRD, Volume 47, Number 4, 2010

Table 5.

Cost projections (in U.S. dollars) from Markov model: Unilateral upper-limb groups ( $n=47$ and 50 for Vietnam and OIF/OEF groups, respectively).

\begin{tabular}{|c|c|c|c|c|c|c|c|c|}
\hline \multirow{2}{*}{ Variable } & \multicolumn{2}{|c|}{$5 \mathrm{Yr}$} & \multicolumn{2}{|c|}{$10 \mathrm{Yr}$} & \multicolumn{2}{|c|}{$20 \mathrm{Yr}$} & \multicolumn{2}{|c|}{ Lifetime } \\
\hline & Vietnam & OIF/OEF & Vietnam & OIF/OEF & Vietnam & OIF/OEF & Vietnam & OIF/OEF \\
\hline$\overline{\text { Mean }}$ & 31,129 & 117,440 & 61,957 & 251,165 & 107,698 & 465,139 & 131,900 & 823,239 \\
\hline SD & 24,340 & 42,625 & 30,745 & 59,545 & 38,610 & 77,415 & 38,287 & 88,742 \\
\hline $2.5 \%$ & 8,039 & 46,677 & 26,187 & 148,558 & 54,836 & 321,363 & 76,471 & 661,117 \\
\hline $10 \%$ & 11,537 & 67,081 & 32,078 & 179,260 & 66,118 & 368,579 & 87,676 & 707,849 \\
\hline $97.5 \%$ & 98,213 & 210,156 & 134,185 & 379,177 & 204,127 & 617,048 & 229,720 & $1,014,324$ \\
\hline Maximum & 172,710 & 369,426 & 249,550 & 498,883 & 315,804 & 766,752 & 299,365 & $1,100,719$ \\
\hline
\end{tabular}

Table 6.

Cost projections (in U.S. dollars) from Markov model: Unilateral lower-limb groups ( $n=178$ and 172 for Vietnam and OIF/OEF groups, respectively).

\begin{tabular}{|c|c|c|c|c|c|c|c|c|}
\hline \multirow{2}{*}{ Variable } & \multicolumn{2}{|c|}{$5 \mathrm{Yr}$} & \multicolumn{2}{|c|}{$10 Y r$} & \multicolumn{2}{|c|}{$20 Y r$} & \multicolumn{2}{|c|}{ Lifetime } \\
\hline & Vietnam & OIF/OEF & Vietnam & OIF/OEF & Vietnam & OIF/OEF & Vietnam & OIF/OEF \\
\hline$\overline{\text { Mean }}$ & 82,251 & 228,665 & 167,848 & 473,951 & 281,234 & 855,907 & 342,716 & $1,463,624$ \\
\hline SD & 13,781 & 43,422 & 20,170 & 60,221 & 25,260 & 80,299 & 27,633 & 105,298 \\
\hline $2.5 \%$ & 56,640 & 159,909 & 131,142 & 371,202 & 234,386 & 716,922 & 290,000 & $1,278,190$ \\
\hline $10 \%$ & 65,016 & 177,646 & 142,413 & 400,314 & 248,761 & 753,570 & 307,240 & 1,330,318 \\
\hline $97.5 \%$ & 110,530 & 320,205 & 209,563 & 602,491 & 331,368 & $1,019,595$ & 397,515 & $1,686,589$ \\
\hline Maximum & 137,645 & 424,167 & 233,077 & 690,358 & 378,605 & $1,274,676$ & 466,227 & $1,841,585$ \\
\hline
\end{tabular}

of Vietnam veterans compared with 94 percent in the OIF/OEF group. The OIF/OEF group use 2.6-fold more devices than the Vietnam group. More of the OIF/OEF group use microprocessor devices $(13 \%)$ than the Vietnam group $(7 \%, p<0.05)$. The average 5 - and 10 -year costs for Vietnam veterans were $\$ 82,251$ and $\$ 167,848$, respectively, compared with \$228,665 and \$473,951, respectively, for the OIF/OEF group.

Findings for veterans and servicemembers with bilateral upper-limb loss appear in Table 7 . Only 50 percent of the Vietnam group $(n=6)$ use prostheses compared with 86 percent in the OIF/OEF group $(n=7)$. The OIF/ OEF group use more than twice the number of prostheses; thus, a wide difference in 5-year average costs is observed: \$90,065 compared with \$333,445. More of the OIF/OEF group with bilateral limb loss use myoelectric devices $(71 \%)$ than the Vietnam group $(17 \%, p<0.05)$.

Table 8 presents results for veterans and servicemembers with other types of multiple limb loss. Prosthe- ses are used by 70 percent of the Vietnam group and 93 percent of the OIF/OEF group. The OIF/OEF group uses over threefold more prostheses than the Vietnam group. More of the OIF/OEF group with multiple limb loss use advanced technology devices (myoelectric or microprocessor) than the Vietnam group (51\% and $14 \%$, respectively, $p=0.01$ ). Five-year average costs for the Vietnam group were $\$ 130,980$ compared with $\$ 453,696$ for the OIF/OEF group.

The distributions in Tables 5 to $\mathbf{8}$ show the variability in projected costs and the uncertainty in transition probability specification. As illustrated in the tables, the standard deviation of costs steadily increase as the length of the projected time horizon increases for both cohorts and all types of limb loss.

Lifetime costs for 298 members of the Vietnam group varied by type of limb loss. The projected costs for the Vietnam veterans (Figure 4) show unilateral upperlimb loss has the lowest lifetime estimated cost of 
Table 7.

Cost projections (in U.S. dollars) from Markov model: Bilateral upper-limb groups ( $n=6$ and 7 for Vietnam and OIF/OEF groups, respectively).

\begin{tabular}{|c|c|c|c|c|c|c|c|c|}
\hline \multirow{2}{*}{ Variable } & \multicolumn{2}{|c|}{$5 \mathrm{Yr}$} & \multicolumn{2}{|c|}{$10 \mathrm{Yr}$} & \multicolumn{2}{|c|}{$20 \mathrm{Yr}$} & \multicolumn{2}{|c|}{ Lifetime } \\
\hline & Vietnam & OIF/OEF & Vietnam & OIF/OEF & Vietnam & OIF/OEF & Vietnam & OIF/OEF \\
\hline$\overline{\text { Mean }}$ & 90,065 & 333,445 & 186,245 & 674,628 & 306,513 & $1,251,827$ & 367,109 & $2,158,244$ \\
\hline SD & 24,637 & 99,704 & 34,938 & 134,858 & 43,824 & 192,623 & 45,833 & 227,935 \\
\hline $2.5 \%$ & 42,116 & 155,159 & 122,803 & 404,725 & 224,583 & 880,748 & 283,022 & $1,731,502$ \\
\hline $10 \%$ & 58,706 & 208,830 & 142,946 & 510,386 & 251,686 & $1,011,698$ & 308,896 & $1,878,160$ \\
\hline $97.5 \%$ & 138,383 & 546,578 & 261,121 & 937,910 & 391,667 & $1,639,430$ & 460,131 & $2,626,264$ \\
\hline Maximum & 159,051 & 682,594 & 313,138 & $1,076,554$ & 434,098 & $2,110,817$ & 507,181 & $2,873,933$ \\
\hline
\end{tabular}

Table 8.

Cost projections (in U.S. dollars) from Markov model: Multiple limb groups ( $n=67$ and 54 for Vietnam and OIF/OEF groups, respectively).

\begin{tabular}{|c|c|c|c|c|c|c|c|c|}
\hline \multirow{2}{*}{ Variable } & \multicolumn{2}{|c|}{$5 \mathrm{Yr}$} & \multicolumn{2}{|c|}{$10 \mathrm{Yr}$} & \multicolumn{2}{|c|}{$20 \mathrm{Yr}$} & \multicolumn{2}{|c|}{ Lifetime } \\
\hline & Vietnam & OIF/OEF & Vietnam & OIF/OEF & Vietnam & OIF/OEF & Vietnam & OIF/OEF \\
\hline Mean & 130,980 & 453,696 & 266,650 & 933,335 & 455,051 & $1,674,333$ & 569,674 & $2,901,365$ \\
\hline SD & 25,768 & 77,714 & 35,963 & 107,370 & 48,820 & 142,539 & 58,282 & 165,399 \\
\hline Minimum & 72,095 & 235,042 & 173,522 & 659,750 & 316,296 & $1,278,076$ & 414,119 & $2,378,366$ \\
\hline $2.5 \%$ & 90,478 & 315,345 & 203,744 & 734,229 & 363,986 & $1,402,603$ & 461,952 & $2,562,500$ \\
\hline $10 \%$ & 100,940 & 359,353 & 221,394 & 801,633 & 393,937 & $1,295,707$ & 494,850 & $2,689,710$ \\
\hline $97.5 \%$ & 192,432 & 616,403 & 342,824 & $1,154,180$ & 557,298 & $1,989,918$ & 689,224 & $3,220,207$ \\
\hline Maximum & 251,243 & 767,878 & 452,730 & $1,299,842$ & 690,155 & 2,162,380 & 750,785 & $3,488,108$ \\
\hline
\end{tabular}

$\$ 131,900$. Bilateral upper-limb loss and unilateral lowerlimb loss mean lifetime costs are similar at \$367,109 and $\$ 342,716$, respectively. Multiple limb loss is associated with the highest mean lifetime cost of $\$ 569,674$. Over longer time spans, costs increase at a decreasing rate because of deaths within each group.

The mean costs for the 283 members of the OIF/OEF group are several times higher than the corresponding costs for the Vietnam group, as shown in Figure 5. This may be a reflection of higher functional levels and the use of more technologically advanced prostheses, use of multiple types of prosthetic devices, and a longer projected length of life from the baseline survey date to the end of life. Average lifetime costs for the OIF/OEF group with unilateral upper-limb loss were the lowest at $\$ 823,299$. Multiple limb loss has the highest average lifetime costs in the OIF/OEF group at \$2,901,365.

A sensitivity analysis was employed on the two cohorts for all modeling scenarios to assess the robust- ness of our transition probability specifications. The results for lifetime costs for the OIF/OEF cohort are shown in Table 9. These results show that the mean projected costs and the standard deviation of costs are very similar to those obtained in Tables 5 to 8. Results (not shown) were similar for the Vietnam cohort and the other time horizons for both groups. Thus, our results appear to be robust with respect to the specification of transition probabilities.

\section{DISCUSSION}

We estimated 5-year, 10-year, 20-year, and lifetime prosthetic and assistive device costs for veterans and servicemembers with major traumatic limb loss associated with combat-theater injury. We found average projected 5 -year costs for prosthetic devices and assistive devices for the OIF/OEF group were 2.8-fold to 3.8-fold higher 


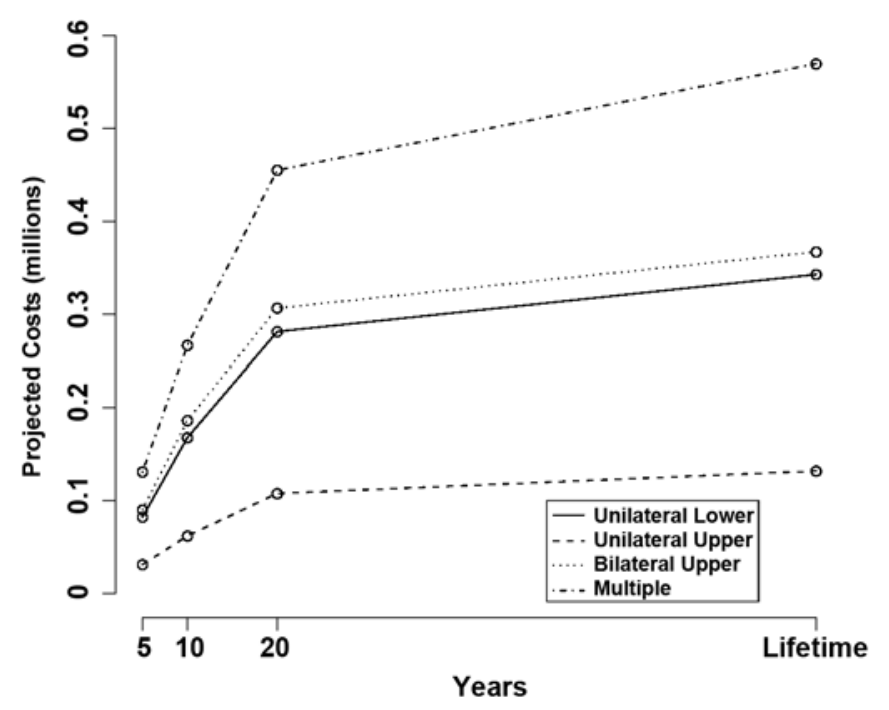

Figure 4.

Average projected costs (in U.S. dollars) following limb loss for Vietnam group (lifetime is $100 \mathrm{yr}$ ).

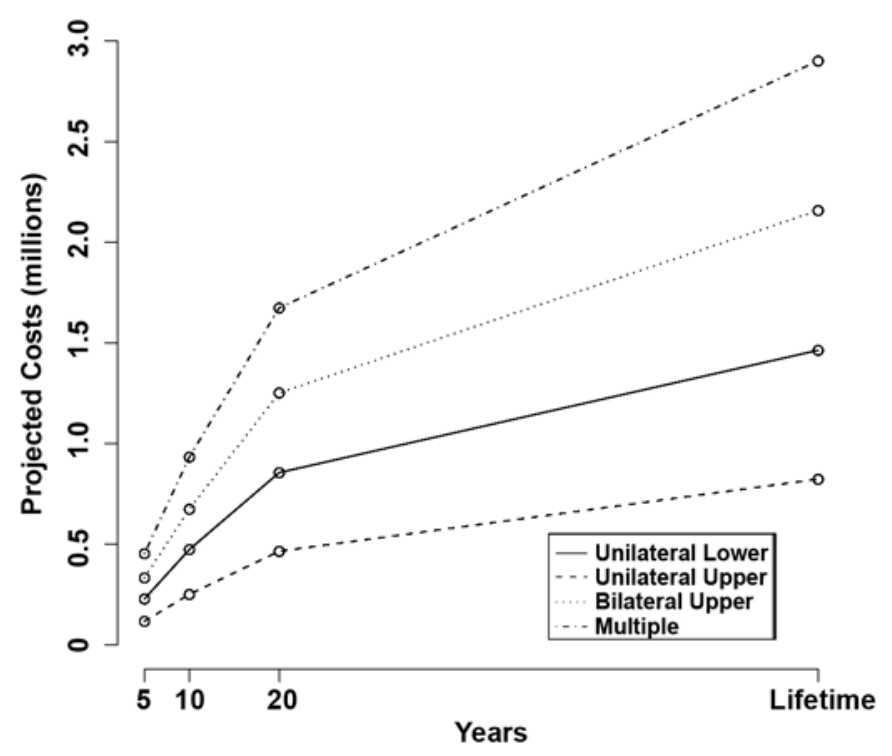

Figure 5.

Average projected costs (in U.S. dollars) following limb loss for Operation Iraqi Freedom/Operation Enduring Freedom group (lifetime is $100 \mathrm{yr}$ ).

than in the Vietnam group. Similarly, 10-year, 20-year, and lifetime costs ranged from 2.8-fold to 6.2-fold higher for the OIF/OEF group. There are several important reasons for these differences.
Reported prosthetic and assistive device use is greater in the OIF/OEF group than the Vietnam group. For assistive device use, 50 percent of the Vietnam group and 57 percent of the OIF/OEF group reported use of a wheelchair [14]. Of survey participants with unilateral upper-limb loss, 30 percent of the Vietnam group and 44 percent of the OIF/OEF group reported current use of assistive devices. For unilateral lower-limb loss, 62 percent of the Vietnam group and 69 percent of the OIF/OEF group currently use assistive devices to aid mobility [14].

Another reason for cost differences between groups is related to the type and average number of prosthetic and assistive devices used by survey participants. Specifically, greater numbers of technologically advanced devices are used by the OIF/OEF group. The current annual rate of reported prosthetic device use by limb-loss level for the OIF/OEF group is 1.8-fold higher/year for unilateral upper-limb loss [12], 2.6-fold higher/year for unilateral lower-limb loss [11], and 15.3-fold higher/year for multiple limb loss [13] than for the Vietnam group.

Historical reimbursement practices for prosthetists and prosthetic devices have typically bundled costs for care, professional services, and devices. While most professional healthcare providers receive reimbursement based on professional services rendered, Medicare and private practice prosthetists receive bundled prosthetic reimbursement that covers all raw materials; purchased components; prosthetists' professional evaluation, fabrication, final fittings, and follow-up adjustments; material and labor overheads; general and administrative costs; and minimal profit. Medicare reimbursement values for prosthetic devices are readily available and accepted and therefore were used in this study.

An initial objective for this study was to compare three costs scenarios for prosthetic device care: Medicare, VA in-house, and private practice. However, variations in costs and pricing practices made this impractical. Privatepractice prosthetics costs are generally assumed to be billings to third-party insurers that reflect base Medicare costs and Medicare nonallowable services. Actual privatepractice costs vary widely amongst practitioners and are not freely published. Certified prosthetists in VA medical center prosthetics laboratories make approximately 5 percent of veterans' prosthetic devices from components. The VA then contracts with nationally accredited local prosthetic-device businesses to produce the remaining 95 percent of the devices. These private prosthetic providers are reimbursed by the VA at 5 to 10 percent 
Table 9.

Sensitivity analysis: Cost projections for “worst case” Dirichlet distribution with all parameters set at 0.3. Operation Iraqi Freedom/Operation Enduring Freedom lifetime costs (in U.S. dollars).

\begin{tabular}{ccccc}
\hline Projected Cost & Unilateral Lower Limb & Unilateral Upper Limb & Bilateral Upper Limb & Other Multiple Limb
\end{tabular}

$\begin{array}{cccc}\text { Mean } \pm \text { SD } & 1,311,571 \pm 150,105 & 877,039 \pm 103,442 & 1,922,782 \pm 227,874\end{array}$

$\mathrm{SD}=$ standard deviation.

below Medicare rates. ${ }^{*}$ We anticipated using the VA Decision Support System (DSS), a national automated management information system that integrates clinical and financial data systems for prosthetics [31], to perform a VA prosthetics cost accounting of veteran-specific prosthetic utilization and costs. The available DSS prosthetics data reviewed at several VA sites were not able to identify veteran-specific components and devices; therefore, this portion of the analysis was not pursued.

We compared our cost estimates with those published in the literature to the extent possible, given that our objective was to project future costs while published literature attempted to summarize current or prior costs. A study by Williams with a population similar to the Vietnam unilateral lower-limb group found costs that compare in order of magnitude to those we obtained for the unilateral lower-limb groups [32]. Williams's analysis lacks a probabilistic framework (necessary measures of uncertainty, such as standard errors). Our review of the literature also identified a limited number of studies involving limb loss and projected costs of prosthetic devices with limited numbers of patients lacking representativeness; thus, these findings cannot be widely generalized [9,33].

Stewart and Jain performed a retrospective study of 98 British veterans from World Wars I and II, the Korean war, and the Falklands war who suffered limb loss [33]. The study used medical records to determine costs, minus those due to residual limb socks, transport, and social security payments. The authors indicate that the resulting average lifetime cost for this group in United Kingdom pound sterling was 69 million (\$111 million United States dollars [USD]) and is likely an underestimate. Measures of uncertainty are not provided, so the generalizability of these results is limited.

\footnotetext{
*Eckrich, Neal. (National Program Director, Prosthetic and Sensory Aids Service, VA Central Office, Washington, DC). Personal communication to: Gayle E. Reiber (Program Analyst, Department of Prosthetic and Sensory Aids, VA Puget Sound Health Care System, Seattle, WA). 2009 Mar 16.
}

Brodtkorb et al. used Markov models in a small study of 20 patients with lower-limb loss to compare the 8-year cost of C-leg prostheses against mechanical prostheses [9]. The study found higher 8-year costs for C-legs (25,146 Euros [\$36,920 USD] vs 17,488 Euros [\$25,679 USD] for mechanical legs). The study did not account for multiple prosthetic use, changing functional states, or lifetime costs.

Our cost estimates add to the body of literature and show differences in the number of prosthetic devices used for the two conflicts. The application of Markov methods was useful to estimate lifetime costs of prosthetic device use. There were no clear clinical guidelines for structuring the model for injured veterans or servicemembers with major limb loss. We outlined our assumptions in the "Methods" section (p. 388). Lack of previous studies and limited published evidence led us to empirically derived costs and opinion-derived probabilities with carefully quantified uncertainty parameters. The results of this study can serve as an aid for VA decision makers in planning for future care of veterans and servicemembers with major limb loss. Through the use of Markov models, our approach not only provides cost projections over a number of time horizons but also includes estimates of uncertainty. The models are based on probability distributions and so have a firm statistical underpinning, given their structure. Our results have face validity when compared with other studies and their estimates of cumulative costs. Thus, our simulation of the two groups of Vietnam veterans and OIF/OEF servicemembers moving through time and accruing costs appears reasonable.

The maximum cost, as indicated in the last row of Tables 5 to 8, is conservative, as it does not include outliers, the cost of future emerging technologies, or advances in surgical procedures. No model can accurately predict outliers (survey participants with extremely large costs), yet such values are typical in medical cost data. Our values indicate a reasonable estimate of how large average cumulative cost might be, given the structure of the model. For example, for the OIF/OEF unilateral lower-limb group, 
even though the expected lifetime costs are approximately $\$ 1.4$ million, the range reaches a high of \$1.8 million.

Research has defined the impact of combat on mental health, physical health, and mortality [34]. Future research is needed to model comorbidities of veterans and servicemembers, including specific physical and mental health conditions. The death rates we used are based on population averages and do not account for specific chronic diseases such as diabetes and posttraumatic stress disorder.

Finally, the Markov model developed in this article is based on functional status with the goal of cost projection. Formal cost-effectiveness analysis was not the purpose of this article. Future studies could focus on both cost and effectiveness.

\section{CONCLUSIONS}

Based on our findings of modest cost increases when projecting prosthetic device use for the next 5,10 , and 20 years and lifetime for the number of veterans and servicemembers from Vietnam and OIF/OEF with traumatic limb loss, future prosthetic healthcare costs may be manageable for the VA and DOD facilities, providing available resources do not change dramatically. The lifetime cost projections do not account for significant changes in health policies or practices. Our study found higher costs associated with the OIF/OEF servicemembers, especially those with multiple limb loss, given the higher number of devices used and newer advanced technologies. The VA and other healthcare provider systems should be prepared for the increase in more advanced technologies and use of multiple prosthetic devices. This preparation for these advanced devices may include training for prosthetists and resources to support their use and maintenance. Future technologies such as the Defense Advanced Research Projects Agency (DARPA) arm [35-36] may dramatically increase future costs. Healthcare providers and policy makers will benefit from an understanding of current cost projections and a uniform approach for coverage of prosthetic and assistive devices for all veterans and servicemembers with major traumatic limb loss.

\section{ACKNOWLEDGMENTS}

Author Contributions:

Study concept and design: D. K. Blough, S. Hubbard, L. V. McFarland, D. G. Smith, J. M. Gambel, G. E. Reiber.
Acquisition of data: S. Hubbard, L. V. McFarland.

Analysis and interpretation of data: D. K. Blough, S. Hubbard, L. V. McFarland, G. E. Reiber.

Drafting of manuscript: D. K. Blough, S. Hubbard, L. V. McFarland, G. E. Reiber.

Statistical analysis: D. K. Blough, L. V. McFarland.

Obtained funding: G. E. Reiber.

Administrative, technical, or material support: S. Hubbard, L. V. McFarland, G. E. Reiber.

Study supervision: L. V. McFarland, G. E. Reiber.

Financial Disclosures: The authors have declared that no competing interests exist.

Funding/Support: This material is based upon work supported by VA Health Services Research and Development Service (grant IIR 05244) and a Career Scientist Award to Dr. Reiber (grant RCS 98-353). The views expressed in this article are those of the authors and do not necessarily reflect the position or policy of the VA or the DOD.

Additional Contributions: Special thanks to Jane Emens and Koriann Brousseau for administrative support on this project.

Institutional Review: Institutional and human subjects' approvals were received from VA Puget Sound Health Care System and Madigan Army Medical Center. A waiver of consent was obtained for survey participants.

Participant Follow-Up: All participants in the survey will receive a copy of the JRRD single-topic issue that includes the publications from this study.

\section{REFERENCES}

1. Pasquina PF, Tsao JW, Collins DM, Chan BL, Charrow A, Karmarkar AM, Cooper RA. Quality of medical care provided to service members with combat-related limb amputations: Report of patient satisfaction. J Rehabil Res Dev. 2008;45(7):953-60. [PMID: 19165685] DOI:10.1682/JRRD.2007.10.0163

2. Reiber GE, McFarland LV, Hubbard S, Maynard C, Blough DK, Gambel JM, Smith DG. Servicemembers and veterans with major traumatic limb loss from Vietnam war and OIF/ OEF conflicts: Survey methods, participants, and summary findings. J Rehabil Res Dev. 2010;47(4):275-98.

3. Maynard C, Flohr B, Guagliardo TA, Martin CH, McFarland LV, Pruden JD, Reiber GE. Department of Veterans Affairs compensation and medical care benefits accorded to veterans with major limb loss. J Rehabil Res Dev. 2010; 47(4):403-8.

4. American Board for Certification in Orthotics, Prosthetics \& Pedorthics. Facility accreditation [Internet]. Alexandria (VA): American Board for Certification in Orthotics, Prosthetics \& Pedorthics [cited 2009 Jul 16]. Available from: http://abc.oandp.com/Facility_Accreditation.asp.

5. Board of Certification/Accreditation, International. BOC Certification \& Certificate Programs [Internet]. Owings 
Mills (MD): BOC International [cited 2009 Jul 16]. Available from: http://www.bocusa.org/BOC.cfm?Page=28.

6. Bondurant FJ, Cotler HB, Buckle R, Miller-Crotchett P, Browner BD. The medical and economic impact of severely injured lower extremities. J Trauma. 1988;28(8): 1270-73. [PMID: 3137367] DOI:10.1097/00005373-198808000-00023

7. Hertel R, Strebel N, Ganz R. Amputation versus reconstruction in traumatic defects of the leg: Outcome and costs. J Orthop Trauma. 1996;10(4):223-29. [PMID: 8723399] DOI:10.1097/00005131-199605000-00001

8. MacKenzie EJ, Jones AS, Bosse MJ, Castillo RC, Pollak AN, Webb LX, Swiontkowski MF, Kellam JF, Smith DG, Sanders RW, Jones AL, Starr AJ, McAndrew MP, Patterson BM, Burgess AR. Health-care costs associated with amputation or reconstruction of a limb-threatening injury. J Bone Joint Surg Am. 2007;89(8):1685-92. [PMID: 17671005] DOI:10.2106/JBJS.F.01350

9. Brodtkorb TH, Henriksson M, Johannesen-Munk K, Thidell F. Cost-effectiveness of C-leg compared with non-microprocessor-controlled knees: A modeling approach. Arch Phys Med Rehabil. 2008;89(1):24-30. [PMID: 18164326] DOI:10.1016/j.apmr.2007.07.049

10. Gerzeli S, Torbica A, Fattore G. Cost utility analysis of knee prosthesis with complete microprocessor control (Cleg) compared with mechanical technology in trans-femoral amputees. Eur J Health Econ. 2009;10(1):47-55.

[PMID: 18379831]

DOI:10.1007/s10198-008-0102-9

11. Gailey R, McFarland LV, Cooper RA, Czerniecki J, Gambel JM, Hubbard S, Maynard C, Smith DG, Raya M, Reiber GE. Unilateral lower-limb loss: Prosthetic device use and functional outcomes in servicemembers from Vietnam war and OIF/OEF conflicts. J Rehabil Res Dev. 2010; 47(4):317-32.

12. McFarland LV, Hubbard Winkler SL, Heinemann AW, Jones M, Esquenazi A. Unilateral upper-limb loss: Satisfaction and prosthetic-device use in veterans and servicemembers from Vietnam war and OIF/OEF conflicts. J Rehabil Res Dev. 2010;47(4):299-316.

13. Dougherty PJ, McFarland LV, Smith DG, Esquenazi A, Blake DJ, Reiber GE. Multiple traumatic limb loss: A comparison of Vietnam veterans to OIF/OEF servicemembers. J Rehabil Res Dev. 2010;47(4):333-48.

14. Laferrier JZ, McFarland LV, Boninger ML, Cooper RA, Reiber GE. Wheeled mobility: Factors influencing mobility and assistive technology in veterans and servicemembers with major traumatic limb loss from Vietnam war and OIF/ OEF conflicts. J Rehabil Res Dev. 2010;47(4):349-60.

15. Hafner BJ, Smith DG. Differences in function and safety between Medicare Functional Classification Level-2 and -3 transfemoral amputees and influence of prosthetic knee joint control. J Rehabil Res Dev. 2009;46(3):417-33.

[PMID: 19675993]

DOI:10.1682/JRRD.2008.01.0007

16. Gailey RS. Predictive outcome measures versus functional outcome measures in the lower limb amputee. J Prosthet Orthot. 2006;18(1S):51-60.

DOI:10.1097/00008526-200601001-00006

17. Centers for Medicare \& Medicaid Services (CMS). CMS Manual System, Pub. 100-04, Medicare Claims Processing: Fee Schedule Update for 2005 for Durable Medical Equipment, Prosthetics, Orthotics, and Supplies (DMEPOS) [Internet]. Washington (DC): Department of Health \& Human Services; 2004 Nov 19 [cited 2009 Mar 12]. Available from: http://www.cms.hhs.gov/transmittals/Downloads/R369CP.pdf.

18. Detsky AS, Naglie G, Krahn MD, Naimark D, Redelmeier DA. Primer on medical decision analysis: Part 1-Getting started. Med Decis Making. 1997;17(2):123-25.

DOI:10.1177/0272989X9701700201

19. Detsky AS, Naglie G, Krahn MD, Redelmeier DA, Naimark D. Primer on medical decision analysis: Part 2-Building a tree. Med Decis Making. 1997;17(2):126-35. DOI:10.1177/0272989X9701700202

20. Krahn MD, Naglie G, Naimark D, Redelmeier DA, Detsky AS. Primer on medical decision analysis: Part 4-Analyzing the model and interpreting the results. Med Decis Making. 1997;17(2):142-51. DOI:10.1177/0272989X9701700204

21. Naglie G, Krahn MD, Naimark D, Redelmeier DA, Detsky AS. Primer on medical decision analysis: Part 3-Estimating probabilities and utilities. Med Decis Making. 1997; 17(2):136-41. DOI:10.1177/0272989X9701700203

22. Naimark D, Krahn MD, Naglie G, Redelmeier DA, Detsky AS. Primer on medical decision analysis: Part 5-Working with Markov processes. Med Decis Making. 1997;17(2): 152-59. DOI:10.1177/0272989X9701700205

23. Weinstein MC, O’Brien B, Hornberger J, Jackson J, Johannesson M, McCabe C, Luce BR; ISPOR Task Force on Good Research Practices-Modeling Studies. Principles of good practice for decision analytic modeling in health-care evaluation: Report of the ISPOR Task Force on Good Research Practices-Modeling Studies. Value Health. 2003; 6(1):9-17. [PMID: 12535234 DOI:10.1046/j.1524-4733.2003.00234.X

24. Briggs AH, Ades AE, Price MJ. Probabilistic sensitivity analysis for decision trees with multiple branches: Use of the Dirichlet distribution in a Bayesian framework. Med Decis Making. 2003;23(4):341-50. [PMID: 12926584] DOI:10.1177/0272989X03255922

25. Arias E. United States life tables, 2002 [Internet]. National Vital Stat Reports. 2004;53(6):1-38. Available from: http:// www.cdc.gov/nchs/data/nvsr/nvsr53/nvsr53 06.pdf. 
26. Vital Statistics of the United States, 1966. Volume II, Section 5. Life Tables. Washington (DC): National Center for Health Statistics; 1968.

27. Briggs A, Sculpher M. An introduction to Markov modelling for economic evaluation. Pharmacoeconomics. 1998;13(4): 397-409. [PMID: 10178664 DOI:10.2165/00019053-199813040-00003

28. Sonnenberg FA, Beck JR. Markov models in medical decision making: A practical guide. Med Decis Making. 1993; 13(4):322-38. [PMID: 8246705] DOI:10.1177/0272989X9301300409

29. Briggs A, Claxton K, Schulpher M. Decision modelling for health economic evaluation. New York (NY): Oxford University Press; 2006.

30. Drummond M, McGuire A. Economic evaluation in health care: Merging theory with practice. New York (NY): Oxford University Press; 2001.

31. Department of Veterans Affairs. VHA Decision Support System (DSS) - Introduction [Internet]. Washington (DC): Department of Veterans Affairs; 2009. [updated 2009 Dec 2; cited 2009 Jul 16]. Available from: http://www.virec.research.va.gov/ DataSourcesName/DSS/DSSintro.htm.
32. Williams MO. Long-term cost comparison of major limb salvage using the Ilizarov method versus amputation. Clin Orthop Relat Res. 1994;(301):156-58. [PMID: 8156666$]$

33. Stewart CP, Jain AS. An epidemiological study of war amputees and the cost to society. Prosthet Orthot Int. 1999; 23(2):102-106. [PMID: 10493136]

34. Kaplan A. Hidden combat wounds: Extensive, deadly, costly. Psychiatr Times. 2006;25(1):1-3.

35. Pope D. DARPA prosthetics programs seek natural upper limb [Internet]. San Francisco (CA): Neurotech Business Report [cited 2009 Jul 16]. Available from: http:// www.neurotechreports.com/pages/darpaprosthetics.html.

36. Applied Physics Laboratory. Revolutionizing Prosthetics 2009 team delivers first DARPA limb prototype. Laurel (MD): Applied Physics Laboratory; 2007 Apr 26 [cited 2009 July 16]. Available from: http://www.jhuapl.edu/ newscenter/pressreleases/2007/070426.asp.

Submitted for publication April 2, 2009. Accepted in revised form November 2, 2009. 